$$
\begin{array}{r}
\text { FE22-94PC4227 } \\
\text { CONF-9507159-- }
\end{array}
$$

Environmental Impacts of Ocean Disposal of $\mathrm{CO}_{2}$

Eric Adams

Senior Research Engineer

Department of Civil \& Environmental Engineering

Nassachusetts Institute of Technology

Howard Herzog

Principal Research Engineer

Energy Laboratory

Massachusetts Institute of Technology

David Auerbach

Graduate Student

Department of Civil \& Environmental Engineering

Massachusetts Institute of Technology

Jennifer Caulfield

Graduate Student

Department of Civil \& Environmental Engineering

Massachusetts Institute of Technology

\title{
Overview
}

One option to reduce atmospheric $\mathrm{CO}_{2}$ levels is to capture and sequester power plant $\mathrm{CO}_{2}$. Commercial $\mathrm{CO}_{2}$ capture technology. though expensive. exists todav. However. the ability to dispose of large quantities of $\mathrm{CO}_{2}$ is highly uncertain. The deep ocean is one of only a few possible $\mathrm{CO}_{2}$ disposal options (others are depleted oil and gas wells or deep. confined aquifers) and is a prime candidate because the deep ocean is vast and highly unsaturated in $\mathrm{CO}_{2}$. The term disposal is really a misnomer because the atmosphere and ocean eventually equilibrate on a timescale of 1000 years regardless of where the $\mathrm{CO}_{2}$ is originally discharged. However. peak atmospheric $\mathrm{CO}_{2}$ concentrations expected to occur in the next few centuries could be significantly reduced by ocean disposal. The magnitude of this reduction will depend upon the quantity of $\mathrm{CO}_{2}$ injected in the ocean. as well as the depth and location of injection.

Ocean disposal of $\mathrm{CO}_{2}$ will only make sense if the environmental impacts to the ocean are significantly less than the avoided impacts of atmospheric release. Our project has been examining these ocean impacts through a multi-disciplinary effort designed to summarize the current state of knowledge. The end-product will be a report issued during the summer of 1996 consisting of two volumes: an executive summary (Vol I) and a series of six, individually authored topical reports (Vol II). A workshop with invited participants from the U.S. and abroad will review the draft findings in January 1996.

The six topical reports cover the following subjects:

(1) $\mathrm{CO}_{2}$ loadings/scenarios

(2) near field perturbations

(3) far field perturbations (performed under subcontract to SAIC, Inc.) 
(4) impacts of $\mathrm{CO}_{2}$ transport (performed under subcontract to UMass-Lowell)

(5) environmental impacts of $\mathrm{CO}_{2}$ release

(6) policy and legal implications of $\mathrm{CO}_{2}$ disposal

Each subject area is summarized briefly below with elaboration given to the near field perturbations and environmental impacts of a dry ice release.

\section{CO. loadings/Scenarios}

A $500 \mathrm{MW}_{e}$ pulverized coal fired power plant is chosen as a reference. Without capture. this plant will emit $\mathrm{CO}_{2}$ to the atmosphere at the rate of $115 \mathrm{~kg} / \mathrm{s}$ (Herzog and Drake, 1993). With ocean disposal we assume $90 \% \mathrm{CO}_{2}$ capture efficiency and a $20 \%$ energy penalty. The energy penalty implies that net energy production with capture is reduced by $20 \%$ for a given energy input or. alternatively, that the required energy input for a given electrical output is increased by $25 \%$. Considering a net electrical output of $500 \mathrm{NIW}_{e}$, the effect of ocean disposal on a standard power plant is summarized below:

\begin{tabular}{|c|c|c|c|}
\hline & $N+D$ & Release of Carbo & $\begin{array}{l}\text { Dioxide } \\
\text { To Ocean }\end{array}$ \\
\hline $\begin{array}{l}\text { Without Capture } \\
\text { With Capture }\end{array}$ & $\begin{array}{l}500 \mathrm{MW}_{e} \\
500 \mathrm{WW}_{e}\end{array}$ & $\begin{array}{l}115 \mathrm{~kg} / \mathrm{s} \\
14.4 \mathrm{~kg} / \mathrm{s}\end{array}$ & $\begin{array}{l}0 \mathrm{~kg} / \mathrm{s} \\
130 \mathrm{~kg} / \mathrm{s}\end{array}$ \\
\hline
\end{tabular}

The emissions loadings are being studied as multiples of the standard power plant. The following matrix summarizes the scenarios that will be investigated:

\begin{tabular}{|c|c|c|c|}
\hline & \multicolumn{3}{|c|}{$\begin{array}{l}\text { Number of } 500 \mathrm{NW}_{e} \text { Power Plants } \\
\left(130 \mathrm{~kg} / \mathrm{s} \mathrm{CO}_{2} \text { per plant }\right)\end{array}$} \\
\hline Analysis & One & Ten & One Hundred \\
\hline $\begin{array}{l}\text { Near Field } \\
(<25 \mathrm{~km})\end{array}$ & $\begin{array}{l}\text { Five injection } \\
\text { scenarios with } \\
\text { generic ambient } \\
\text { conditions } \\
\end{array}$ & $\begin{array}{l}\text { Five injection } \\
\text { scenarios with } \\
\text { generic ambient } \\
\text { conditions } \\
\end{array}$ & - \\
\hline $\begin{array}{l}\text { Mesoscale } \\
(25 \mathrm{~km}-2500 \mathrm{~km})\end{array}$ & & $\begin{array}{l}3-5 \text { specific sites } \\
\text { off eastern U.S. with } \\
\text { a generic injection } \\
\text { at depth of } 1000 \mathrm{~m} \text {. }\end{array}$ & \\
\hline $\begin{array}{l}\text { Far Field } \\
(300 \mathrm{~km} \text {-global })\end{array}$ & - & - & $\begin{array}{l}\text { One scenario: } \\
50 \% \text { injected at } \\
1000 \mathrm{~m} \text { off Tokyo } \\
\& 50 \% \text { injected at } \\
1000 \mathrm{~m} \text { off New York }\end{array}$ \\
\hline
\end{tabular}

One power plant is essentially the lowest level of disposal anticipated while the emissions from ten power plants represent an upper limit on the amount of emissions that are expected to be disposed of at a single point for reasons of economy of transport. One 
humdred plants represents a loading of about $1.6 \%$ of the world's total anthopogenic $\mathrm{CO}_{2}$ emissions and. as such. is a lower bound on the global amount of ocean disposial which could "make a difference" to atmospheric $\mathrm{CO}_{2}$ levels.

For the near field analysis. five injection scenarios are considered:

- a droplet plume injected at $1000 \mathrm{~m}$

- a $\mathrm{CO}_{2}$ lake on the ocean bottom below $3700 \mathrm{~m}$

- i dense $\mathrm{CO}_{2}$ seawater plume injected at or below $500 \mathrm{~m}$

- dry ice cubes released from the ocean surface

- a $\mathrm{CO}_{2}$ hydrate plume injected at or below $500 \mathrm{~m}$

\section{Near Field Perturbations}

The five injection scenarios are evaluated using separate models to describe $3-D$ concentration distributions of excess $\mathrm{CO}_{2}$ and trace gases such as $\mathrm{SO}_{2}$ and $\mathrm{NO}_{\mathrm{x}}$. The principal impacts of each scenario - the decrease in $\mathrm{pH}$ - are quantified using two criteria. First the spatial distribution of $\mathrm{pH}$ change is calculated. Then the range of time-histories of passive organisms traveling through the plume is calculated. Absolute $\mathrm{pH}$ is used in orcler to correlate the experiences with appropriate mortality data.

\section{Far Field Perturbations}

Far field perturbations refer to the change in total $\mathrm{CO}_{2}$ concentration and associated $\mathrm{pH}$ at mesoscale and global scale.

Mesoscale simulations are being run for various locations along the eastern U.S.. The mesoscale dispersion model is a stochastic particle model driven by an externally calculated. time-dependent 3-D velocity field. "Particles" of $\mathrm{CO}_{2}$ are continuously released at an injection site of $1000 \mathrm{~m}$ and tracked as they are advected by ocean currents. which include a mean current and turbulent fluctuations. The concentration of $\mathrm{CO}_{2}$ at any one time can be plotted at a resolution of $1 / 4 \times 1 / 4$ degrees latitude and longitude.

A global carbon cycle model is being used to predict far-field long-term pertubations associated with one hundred $500 \mathrm{MW}_{e}$ powerplants: 50 off of Tokyo and 50 off of New York. Injection depths of $1000 \mathrm{~m}$ will be used and simulations will run through the year 2500. The global discharge of anthropogenic $\mathrm{CO}_{2}$ will be modeled as a simple logistics function of time. The global cycle model is based on the non-biological ocean circulation model of Mairer-Riemer and Hasselmann (1987), with biological carbon cycle components described by Bacastow and Mairer-Riemer (1990).

\section{Environmental Impacts of $\mathrm{CO}_{2}$ Transport Systems}

Enviromental impacts may occur at several stages of transport. The major impact of on-shore pipes occurs during construction when vegetation must be cleared and trenches dug. After construction. land and vegetation needs to be restored. In populated areas. it may be difficult to obtain rights-of-way. There is a remote chance of pipe rupture with the release of vaporized $\mathrm{CO}_{2} . \mathrm{CO}_{2}$ is not toxic, but is an asphyxant. Models are being used to estimate the dispersal of this dense vapor and the risk to the surrounding environment.

The major impact of off-shore pipes will also occur during pipe-laying. The first few kilometers will be laid on the continental shelf which may include coral beds. sea vegetation and other marine habitats. Accidental rupture of the pipe would release $\mathrm{CO}_{2}$

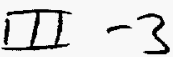


into the seawater, with partial dissolution. The rest of the released $\mathrm{CO}_{2}$ would anpidiv bubble up to the surface and reenter the atmosphere. The dissolved $\mathrm{CO}_{2}$ will callse. acidification of the seawater in the vicinity of the ruptured pipe.

The environmental impacts of tanker transport include (a) accidental releases with possible injury to the tanker crew: (b) release into the atmosphere of fuel combustion gases and particles. Both diesel and steam propelled tankers release into the atmosphere particles (flyash and soot), $\mathrm{SO}_{2}$ and $\mathrm{NO}_{x}$, and of course $\mathrm{CO}_{2}$.

For pipe transport. on-shore facilities include a pumping station and storage tanks. Construction may require coastal land acquisition and disruption of coastal habitat. There is also a remote risk of accidental release of pressurized, liquid $\mathrm{CO}_{2}$. For tanker transport, docking facilities will be required in existing harbors, or specially built ports.

If tanker transport is used for deep sea disposal, floating platforms must be used to unload $\mathrm{CO}_{2}$ and pump it into a pipe extending from the platform. The Hoating platforms will cause minimal impact but may be a navigation hazard. The operating crew on the platform will be exposed to storms and other environmental hazards. is well as possible accidental release of pressurized, liquid $\mathrm{CO}_{2}$. The vertical pipe should not cause significant impact on the marine environment.

\section{Environmental Impacts of Ocean Disposal of $\mathrm{CO}_{2}$}

Marine life can be classified into four groups: phytoplankton. zooplankton. nekton. and benthos. The groups that will be affected by a $\mathrm{CO}_{2}$ plume depend on the injection scenario and many scenarios preclude certain types of organisms from harm. The dry ice scenario is discussed below, but the methods and considerations are applicable to other scenarios.

\section{Policv and Legal Implications of $\mathrm{CO}_{2}$ Disposal}

Important considerations relate both to site-specific discharges within or neir a country's Exclusive Economic Zone as well as large scale worldwide $\mathrm{CO}_{2}$ disposal. The Law of the Sea and the United Nations Environment Programme Agenda 21 are tonesetting and establish our committment to curb $\mathrm{CO}_{2}$ emissions. The London Dumping Convention. as well as other regional treaties, are more specific and classify materials. prohibiting the discharge of some to the ocean.

Worldwide $\mathrm{CO}_{2}$ disposal would require international cooperation and funding. Presumably it would not be initiated without consensus that avoided impacts/risks of global change outweigh any impacts to the ocean. In opposition to this philosophy. international treaty language is moving toward a precautionary principle and frowns upon end of pipe solutions or solutions which transfer pollution from one medium (air) to another (water). Furthermore, the emotional response of non-governmental organizations (NGOs) can not be discounted.

\section{Analysis for Dry Ice Disposal}

The near field perturbations and associated environmental impacts for dry ice injection are considered as an example our methodology. Dry ice cubes must be as large as practical. to insure that only a small fraction of the dissolution occurs near the surface. Cubes with 3 meter sides released from a fixed point were chosen; one standard power plant requires the release of one cube every 320 seconds. $\mathrm{CO}_{2}$ dissolution to the water column as a function of depth was based on Nakashiki et al. (1991).

To obtain a steady state solution the release was approximated as a continuous line source. Turbulence induced by the falling cube was added to a scale-dependent ambient 
diffusivity (Okubo, 1973) to obtain the total diffusivity as a function of distance. The solution for the excess total $\mathrm{CO}_{2}$ concentration is then given by

$$
C(x, y, z)=\frac{\dot{M} / u}{\sqrt{2 \pi} \sigma} \exp \left(\frac{-y^{2}}{2 \sigma^{2}}\right)
$$

where $\dot{H}(z)$ is the mass flux ( $\mathrm{kg} / \mathrm{m}-\mathrm{s})$ at depth $z, u$ is the current speed $(\mathrm{m} / \mathrm{s})$, and $\sigma(x)$ is the lateral standard deviation $(m)$ found from the total diffusivity.

Excess $\mathrm{CO}_{2}$ concentrations due to the disposal of dry ice were calculated for the one and the ten plant scenarios for $u=0.02$ and $0.10 \mathrm{~m} / \mathrm{s}$. Results for one plant with $u=0.02 \mathrm{~m} / \mathrm{s}$ current are shown in Figure 1 . The excess $\mathrm{CO}_{2}$ was added to the ambient $\mathrm{CO}_{2}$ to compute new pHs. A map of the change in $\mathrm{pH}$ can be seen in Figure 2.

The average ocean $\mathrm{CO}_{2}$ concentration experienced by an organism passing through the region can be calculated by assuming that the organism is subject to the same diffusivity as the $\mathrm{CO}_{2}$. Thus

$$
\bar{C}\left(x, y_{0}, z\right)=\frac{C_{\max }}{\sqrt{2}} \exp \left(\frac{-y_{0}^{2}}{2 \sigma^{2}}\right)
$$

where $\bar{C}\left(x, y_{z}\right)$ is the average excess $\mathrm{CO}_{2}$ concentration experienced at location $x$ and $z$ by an organism that passes through the plume at a lateral distance $y_{0}$ from the source. and $C_{\max }(x)$ is the concentration at the centerline $(y=0)$ given above. $\bar{C}$ is used to calculate average $\mathrm{pH}$ as a function of time. At each depth, several lateral sections are selected and a representative experience is found based on the value of $y_{0}$ at the middle of each section. Figure 3 shows the experiences at a depth of $900 \mathrm{~m}$ for ten power plants in a $0.02 \mathrm{~m} / \mathrm{s}$ current.

The environmental impact assessment focuses on zooplankton and assumes conservatively that they have no $\mathrm{CO}_{2}$ avoidance ability. Knowing the volume of water that will experience a given time history of $\mathrm{pH}$. and knowing the population density of organisms in the water is sufficient to estimate the numbers of zooplankton affected by the $\mathrm{CO}_{2}$.

Most studies on the effects of $\mathrm{pH}$ have been on fish in acidified lakes in response to acid rain concerns. Still, several useful studies have been performed on marine zooplankton in which either the animals were exposed to a constant $\mathrm{pH}$. and mortality assessed at different times, or the animals were exposed to various $\mathrm{pHs}$ for a given time and mortality assessed (Grice et al., 1973, Calabrese et al., 1966. Havas and Hutchinson 1982 and Bamber 1987). Results from these studies have been superimposed on Figure 4 to give an approximate map of expected mortality as a function of $\mathrm{pH}$ and exposure time. ('Isomortality' curves are drawn for $0 \%, 50 \%$, and $90 \%$ mortality as guides.)

Near field output such as Figure 3 can be discritized to yield the number of hours over which various sections of the plume experience different values of $\mathrm{pH}$. The cumulative impact of a time-varying exposure can be estimated by using the isomortalilty curves to convert exposures into a common metric. For example, on Figure 4, an exposure of 50 hours at pH 6.0 causes roughly the same $10 \%$ mortality as an exposure of 15 hours at $\mathrm{pH} 5.5$. Hence we can approximate an exposure of 50 hours at 6.0 plus 10 hours at 5.5 as 25 hours at 5.5. For such an exposure, the graph gives a mortality of $50 \%$. Equivalently, converting the exposures to a metric of hours at 6.0 instead of 5.5 , gives a total exposure of 90 hours corresponding to about $40 \%$ mortality. The table below illustrates this procedure using data from Figure 3 and compares it with an alternative method (Schubel, 1978). 


\begin{tabular}{|c|c|c|c|c|c|c|}
\hline $\begin{array}{l}\text { Section width } \\
\text { (m) }\end{array}$ & $\underset{5.5}{\text { hrs. at }}$ & $\begin{array}{l}\text { hrs. at } \mathrm{pH} \\
6.0\end{array}$ & hrs. at ${ }_{6.5} \mathrm{pH}$ & $\begin{array}{c}\text { hrs. at } \mathrm{pH} \\
7.0\end{array}$ & $\begin{array}{c}\text { mortality } \\
\% 1\end{array}$ & $\begin{array}{c}\text { mortality } \\
\%, 2\end{array}$ \\
\hline $0-20$ & .417 & 2.71 & 5.97 & 14.8 & $0 \%$ & $2.2 \%$ \\
\hline $20-60$ & 0 & .90 & 7.71 & 15.0 & $0 \%$ & $1.3 \%$ \\
\hline $60-120$ & 0 & 0 & 6.39 & 16.0 & $0 \%$ & $1.0 \%$ \\
\hline $120-240$ & 0 & 0 & 0 & 19.4 & $0 \%$ & $0.5 \%$ \\
\hline
\end{tabular}

mortality $\% 1=$ mortality using method described above. $\% 2=$ mortality following Schubel (1978)

The section in the first row above is closest to the plume centerline and would experience the greatest effect; these data are plotted in Figure 4. It is clear that even the most severely affected organisms would scarcely be affected (method 2 by design will give non-zero mortalities since it assumes no threshold but these small numbers should be considered artifacts). Thus, we can safely expect little or no harm to pelagic. organisms from the scenario of falling dry ice cubes. It should be mentioned that yhe dry ice cube scenario is expected to have the least impact because of the large dilution. We are in the process of studying other injection scenarios using similar methodology.

\section{$\underline{\text { References }}$}

Bacastow. R. and E. Maier-Reimer (1990). "Ocean-circulation model of the carbon cycle" Clim. Dyn. 4:95-125.

Bamber. R.N. (1987). "The effects of acidic seawater on young carpet-shell clams Venerupis decussata $(\ell)$ (Mollusca: Veneracea)" "Journal of Experimental Marine Biology and Ecology; 108:241-260.

Calabrese, A.. and H.C. David (1966). "The pH tolerance of embryos andlLarvae of Mercenaria mercenaria and Crassotrea virginica" Biological Bulletin, 131:42 $7-436$.

Grice, G.D.. E. Hoagland and P.H. Wiebe (1973). "Acid-iron waste as a factor affecting the distribution and abundance of zooplankton in the New York Bight" Estuarine and Coastal Marine Science 1:45-50.

Havas, M. and T.C. Hutchinson (1982). "Effects of low pH on the chemical composition of aquatic invertebrates from tundra ponds at the Smoking Hills, N.W.T. Canada" Canadian Journal of Zoology 61:241-249.

Herzog, H.J. and E.M. Drake (1993). "Long-Term Advanced $\mathrm{CO}_{2}$ Capture Options": IEA Greenhouse Gas R\&D Programme Report, IEA/93/OE6.

Maier-Reimer, E. and K. Hasselmann (1987). "Transport and storage of $\mathrm{CO}_{2}$ in the ocean - an inorganic ocean-circulation carbon cycle model" Clim. Dyn. 2:63-90.

Nakashiki,N., T. Ohsumi, and K. Shitashima (1991). "Sequestering of $\mathrm{CO}_{2}$ in the deepocean: Fall velocity and dissolution rate of solid $\mathrm{CO}_{2}$ in the ocean" Central Research Institute of Electric Power Industry, Technical Report EU91003.

Okubo. A. (1971). "Oceanic diffusion diagrams" Deep-Sea Research 18:789-802.

Schubel, J. R., C.C. Coutant, and P.M.J. Woodhead (1978). "Thermal effects of entrainment" in Power Plant Entrainment, A Biological Assessment (Schubel, J.R. Marcy. B.C. Jr. eds) Academic Press Inc., New York. 
Figure 1: Additional $\mathrm{CO}_{2}$ concentrations due to the addition of the emissions of one standard power plant as 3 meter blocks of dry ice

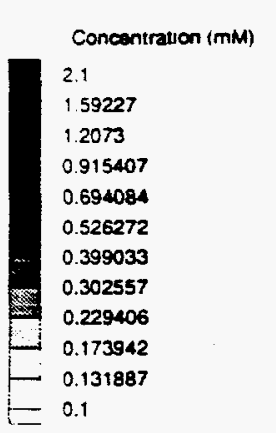

Distance (meters)

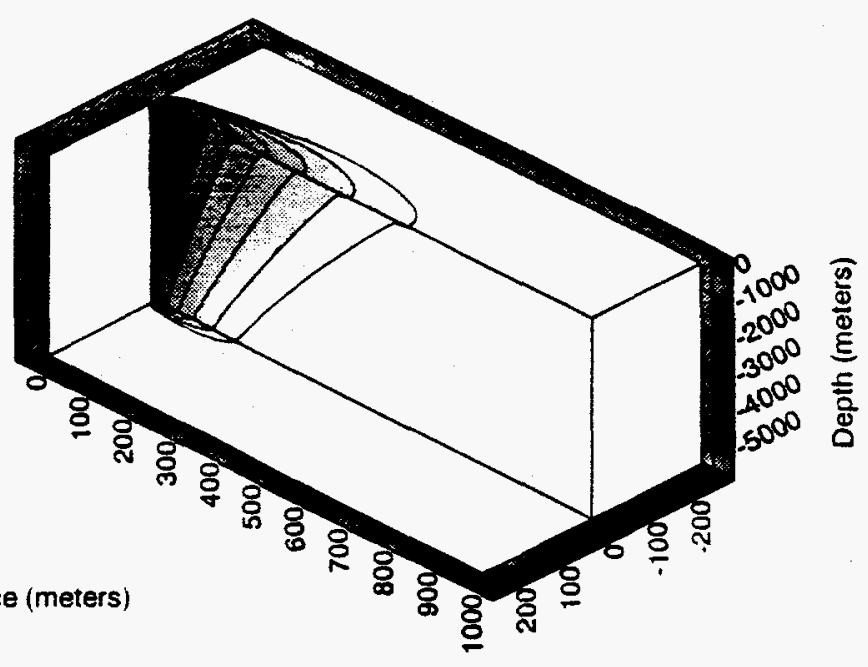

Figure 2: Change in $\mathrm{pH}$ resulting from dry ice addition

$=\begin{gathered}\text { CHANGE,H } \\ 1.341 \mathrm{H}^{-7} \\ -0.2 \\ -0.4 \\ -0.6 \\ -0.8 \\ -1 \\ -1.2 \\ -1.4 \\ -1.6 \\ -1.8 \\ -2 \\ -2.2 \\ -2.4 \\ -2.6\end{gathered}$

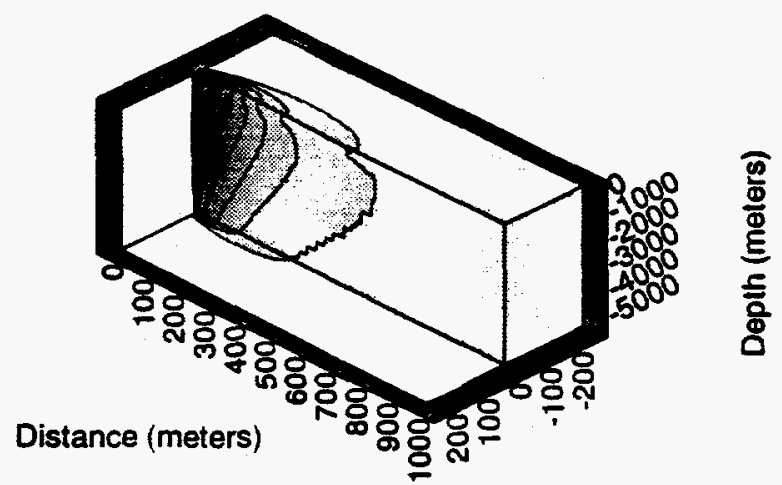

Emissions from 1 power plant in a $0.02 \mathrm{~m} / \mathrm{s}$ current

$$
\text { III-7 }
$$


Figure 3: $\mathrm{pH}$-Time experience for organisms at different distances rom the piume centerline (conditions at a depth of 900 meters)

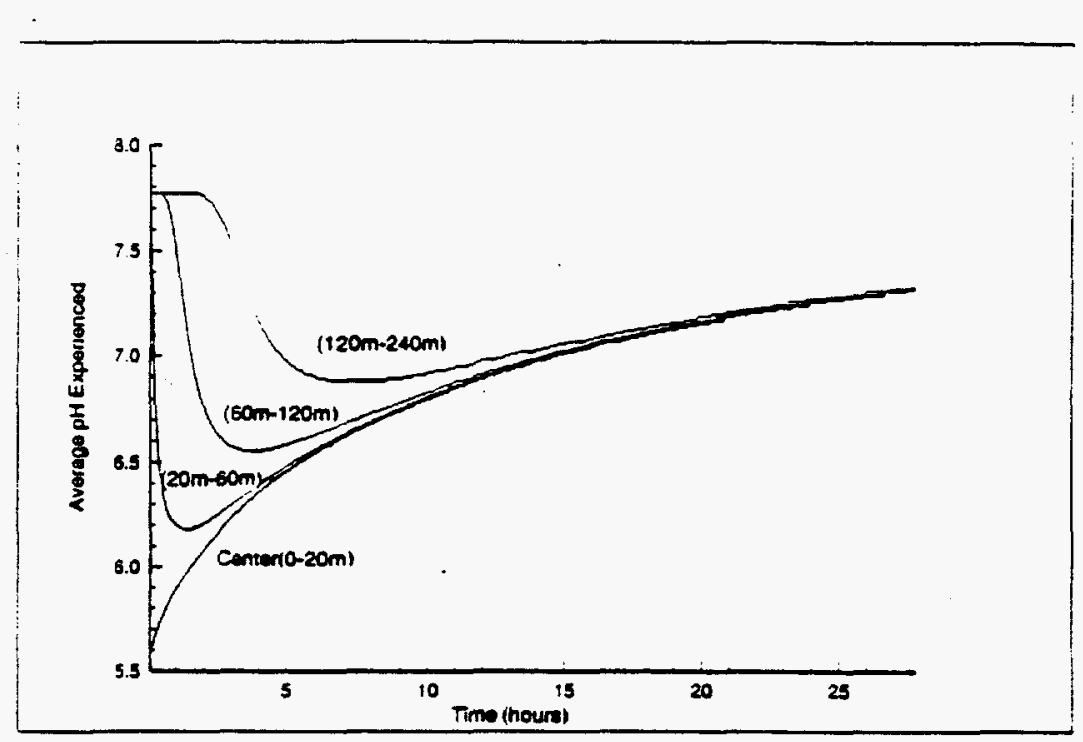

Figure 4: Mortality of zooplankton

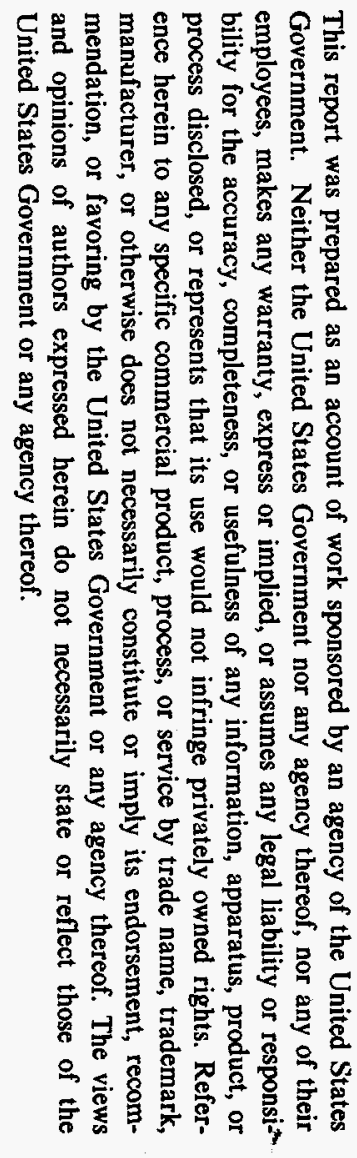

Mortality of Zooplankton

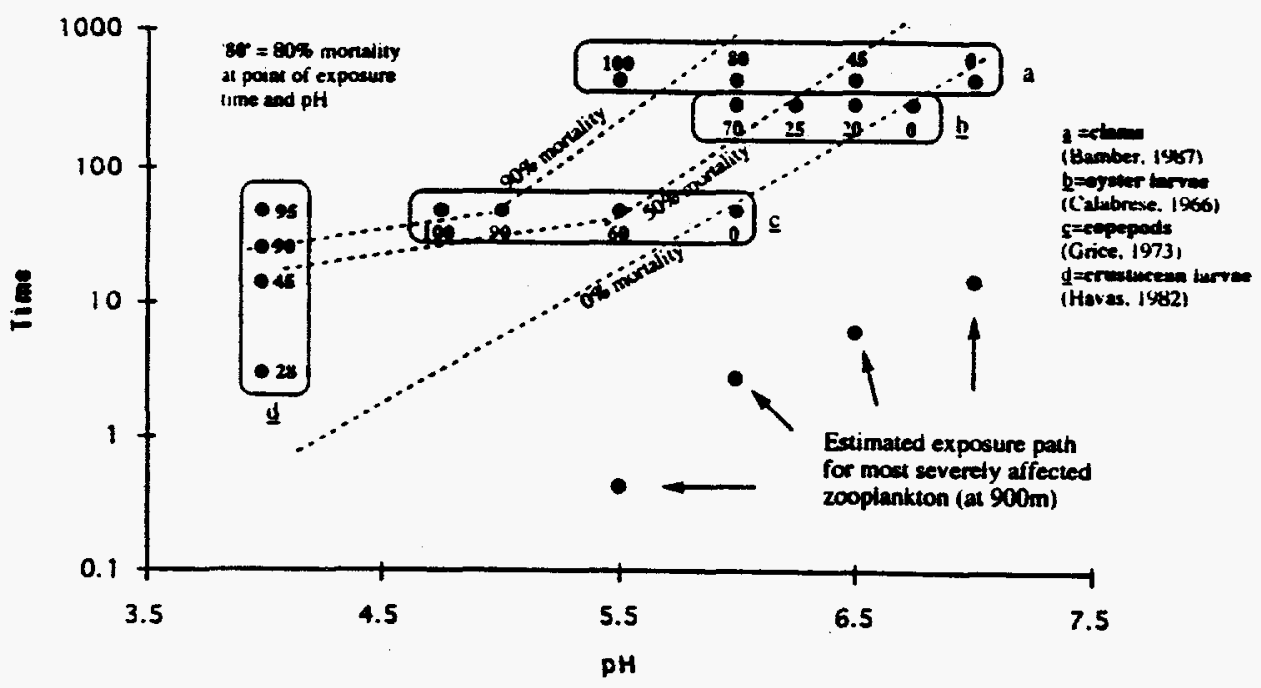




\section{ATTACHMENT III}

Paper to be presented at the

\section{Eleventh Annual Coal Preparation, Utilization, and Environmental Control}

Contractors Conference

Pittsburgh, PA

$$
\begin{aligned}
& \text { Rempred for } \\
& \text { separale cyclug a }
\end{aligned}
$$

July 12, 1995 